\title{
Measuring bacterial ectoenzyme activities in marine waters using mercuric chloride as a preservative and a control
}

\author{
James R. Christian, David M. Karl \\ School of Ocean and Earth Science and Technology, University of Hawaii, Honolulu, Hawaii 96822, USA
}

\begin{abstract}
Investigations of bacterial ectoenzymes in seawater using fluorogenic substrate analogues such as 4 -methylumbelliferone (4MUF) and $\beta$-naphthylamine (BNAPH) are made more efficient and feasible in a greater range of environments if samples can be preserved and analyzed at a later date. Preservation by freezing has been shown to be feasible. However, activity will persist in the liquid phase until the samples are completely trozen and will commence again upon thawing. Addition of mercuric chloride $\left(\mathrm{HgCl}_{2}\right)$ is an excellent means of terminating enzymatic activity, as well as providing a negative control for autofluorescence and autohydrolysis without the need to boil or autoclave seawater. $\mathrm{HgCl}_{2}$ causes relatively little inhibition of fluorescence $4 \mathrm{MUF}(\sim 5 \%)$ and BNAPH $(\sim 30 \%)$ in seawater. Furthermore, the effects are linear over a wide range of concentrations and consistent across the excitation and emission spectra. Inhibition of $4 \mathrm{MUF}$ fluorescence by $\mathrm{Hg}^{2+}$ in solutions of low ionic strength is reversible by addition of $\mathrm{NaCl}$ or other salts, so this method of preservation may be useful in fresh waters as well. $4 \mathrm{MUF}$ fluorescence in $\mathrm{Hg}^{2+}$-poisoned seawater is stable for long periods ( $\left.>1 \mathrm{yr}\right)$ when stored in the dark at $-20^{\circ} \mathrm{C}$; $\mathrm{BNAPH}$, however, loses fluorescence over time.
\end{abstract}

KEY WORDS: Bacteria - Seawater - Ectoenzymes - Fluorescence - Mercuric chloride Preservation

\section{INTRODUCTION}

Use of fluorogenic tracers to determine bacterial ectoenzymatic activity in marine and fresh waters has become widespread in the past decade (Chróst 1991). Because of its utility in determining rates and patterns of bacterial utilization of dissolved organic matter (DOM), and the relative ease of measurement, this is becoming one of the cornerstone methods of aquatic microbial ecology (Hoppe 1991, 1993). Most studies of ectoenzymes to date have been in freshwater, estuarine and nearshore marine environments (Chróst 1991); the overwhelming majority have been in the temperate zones. Oceanic and high-latitude environments present difficulties that can be alleviated by having a convenient and reliable preservative. We have found mercuric ion $\left(\mathrm{Hg}^{2+}\right)$ to be a suitable preservative in marine waters of relatively constant salinity.

Mercuric ion is toxic to virtually all organisms, because it irreversibly denatures most enzymes by forming covalent cross-linkages among $\mathrm{R}$ groups, particularly sulfhydryls (Royer 1982). This mode of inhibition makes it an ideal poison for working with ectoenzymes, because other poisons used to inhibit whole-cell processes (e.g. chloroform, $\mathrm{NaN}_{3}$ ) may not affect individual enzymes external to the cell.

Most investigators of ectoenzymes have avoided using poisons, possibly because they sought to develop methods for fresh water or methods suitable for both fresh and seawater. Mercuric ion greatly reduces the fluorescence yield of 4 -methylumbelliferone (4MUF) in fresh water. In salt water this is not the case, probably because other cations such as sodium and magnesium compete with $\mathrm{Hg}^{2+}$ for attachment to the fluorogen molecules. This effect of sea salt ions provides investigators of ectoenzymes in marine habitats with a fast and reliable method for preserving samples for later analysis and controlling for autohydrolysis and autofluorescence of the substrate analogue. 
Samples incubated with 4MUF derivatives at sea may be frozen without significantly affecting the fluorescence (Chróst \& Velimirov 1991). Adding $\mathrm{HgCl}_{2}$ prior to freezing allows large numbers of samples to be thawed simultaneously without introducing errors associated with enzyme activity in the thawing samples, and obviates the need for strict temperature control. Without a preservative samples must be thawed at near-freezing temperature and the fluorescence measured under strict temperature control. Even if these precautions are taken one must correct for activity in the liquid phase after thawing, which is difficult because the kinetic parameters of the reaction are altered by freezing (Chróst \& Velimirov 1991) and represents a particularly serious problem if the temperature in situ is near freezing, as for example in Antarctic waters

When working at sea a method that permits storage of samples is extremely desirable. The measurements can be made even if the primary analyst has many other commitments, and samples will not be lost if the weather abruptly turns rough. If the incubation period is long, as it must be in oligotrophic waters, the incubation will frequently be completed at inconvenient times; poisoning and freezing the samples takes little time, and they can then be measured when time permits or returned to shore-based laboratories

Another problem that must be faced at sea is the deterioration of the reagents. Ideally reagents should be made up fresh before each experiment but in seagoing programs this is rarely possible. The reagents are stable for a long time if properly stored, but background fluorescence increases over time, so it is necessary to have a control for this each time incubations are carried out. $\mathrm{Hg}^{2+}$-poisoned seawater provides a reproducible and reliable control for autohydrolysis.

A major advantage of using $\mathrm{HgCl}_{2}$ is that it makes the whole process less labour-intensive and allows the analyst to process a greater number of samples. In addition, instrument warm up time and the short shelf life of external fluorescence standards make it desirable to run many samples of a given type in a single sitting, rather than starting the instrument to read only a few samples.

This paper describes the use of mercuric chloride as a convenient method of preservation in studies of ectoenzymes using the fluorogenic substrate analogues 4MUF and $\beta$-naphthylamine (BNAPH). The effects of mercuric chloride on fluorescence of $4 \mathrm{MUF}$ and BNAPH are shown to be relatively small and predictable in seawater and spectral effects absent. Longterm storage experiments show that fluorescence is retained for long periods in frozen seawater samples. Field data show that this method offers great precision and sensitivity when working in oligotrophic waters.

\section{MATERIALS AND METHODS}

Methods for ectoenzyme analysis were adapted from Hoppe (1983) and Somville \& Billen (1983); see also Hoppe (1993) . 4MUF and BNAPH were obtained from Sigma Chemical Co. Stock solutions were made up in distilled, deionized water (ddw) to a final concentration of $100 \mu \mathrm{M}$. 4MUF $(-20 \mathrm{mg})$ was first dissolved in $2 \mathrm{ml}$ methyl cellosolve (2-methoxyethanol; Sigma Chemical Co.), then diluted to $1 \mathrm{l}$ with ddw. BNAPH ( 15 mg) was dissolved directly in 1 l ddw by heating in a glass bottle with magnetic stirring (BNAPH should first be crushed to a fine powder to accelerate dissolution). The liquid was brought to boiling, then the heat was reduced to just less than $100^{\circ} \mathrm{C}$ and the bottle kept loosely capped to minimize evaporation. BNAPH can also be dissolved in methyl cellosolve, although there is a small loss of fluorescence relative to standards prepared in the manner described above.

These stock solutions were serially diluted to concentrations of 10,1 , and $0.1 \mu \mathrm{M}$ in ddw and 100,200 , and $500 \mu \mathrm{l}$ aliquots of these solutions were added to $6 \mathrm{ml}$ of seawater. Fluorescence was determined in a Perkin-Elmer LS-5 spectrofluorometer with quartz or polymethacrylate (Sigma Chemical) cuvettes. Polymethacrylate has transmission properties similar to quartz for wavelengths greater than $\sim 300 \mathrm{~nm}$. Excitation/emission wavelengths were centred on $360 /$ $447 \mathrm{~nm}$ for $4 \mathrm{MUF}$ and $337 / 411 \mathrm{~nm}$ for BNAPH with a bandwidth of $10 \mathrm{~nm}$.

Stock solutions of the fluorescent substrate analogues were prepared in much the same way, with methyl cellosolve used in 1:500 ratio for 4MUF derivatives. L-leucyl- $\beta$-naphthylamine (Somville \& Billen 1983 ) is water soluble at room temperature and does not require methyl cellosolve.

\section{RESULTS}

The fluorescence yield of $4 \mathrm{MUF}$ in seawater poisoned with $\mathrm{HgCl}_{2}$ (final concentration $4 \mathrm{mM}$ ) was approximately $5 \%$ less than in unpoisoned seawater, over a wide concentration range (Fig. 1a). Reduction in fluorescence was greater for BNAPH $(-30 \%)$ but the percent loss was constant over a concentration range of at least 3 orders of magnitude (Fig. 1b). Standard curves could be fitted to a straight line, with $r^{2}$ always $>0.99$ and usually $>0.999$. In oligotrophic waters the 'turbidity effect' due to particulate matter is minimal; filtering may be necessary in eutrophic waters.

To determine the effect of the ionic strength of the menstruum on the reduction of fluorescence yield by $\mathrm{Hg}^{2+}$, we prepared solutions of $\mathrm{NaCl}, \mathrm{MgCl}_{2}$, and 

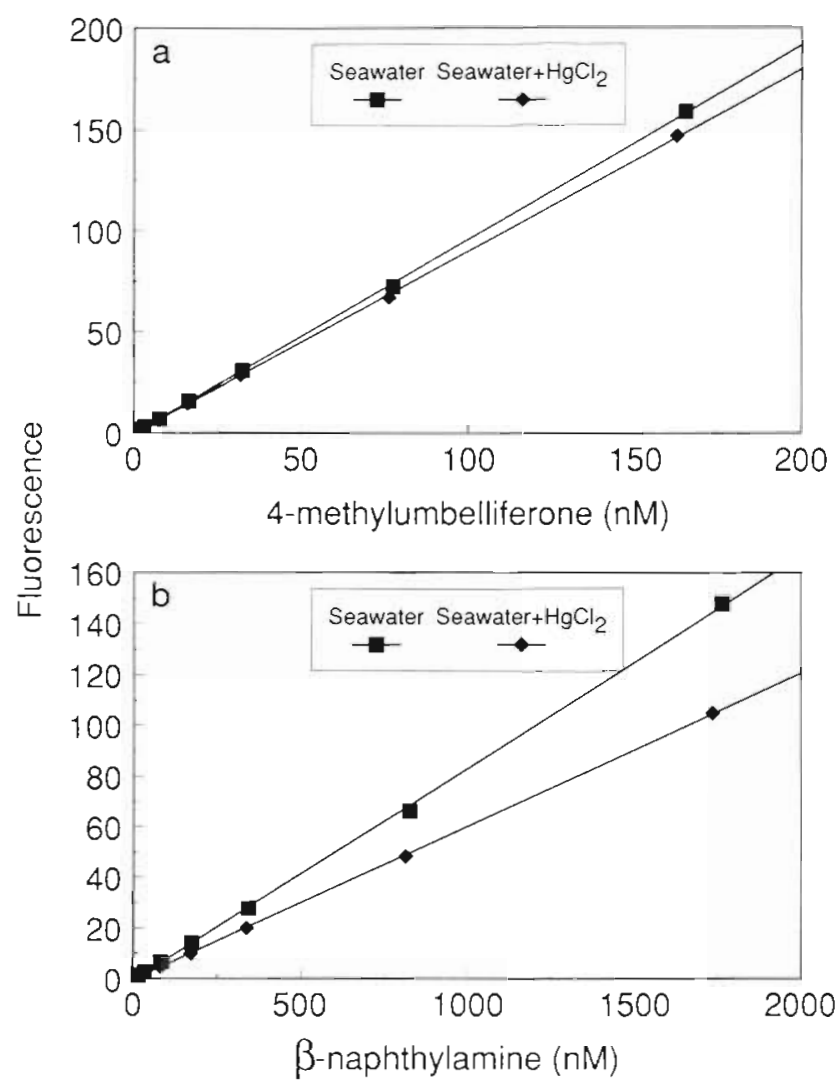

Fig. 1. Fluorescence (arbitrary units) versus concentration for (a) 4-methylumbelliferone and (b) B-naphthylamine in subtropical North Pacific surface seawater with and without $4 \mathrm{mM} \mathrm{HgCl}_{2}$

$\mathrm{NaHCO}_{3}$ at concentrations approximately equivalent to their molarities in seawater at $35 \%(585,50$, and $2 \mathrm{mM}$, respectively). $\mathrm{NaCl}$ and $\mathrm{MgCl}_{2}$ solutions also contained $2 \mathrm{mM} \mathrm{NaHCO}$ to buffer against $\mathrm{pH}$ changes.

Fig, 2a shows the relative fluorescence yield of $4 \mathrm{MUF}$ in these 3 solutions and in seawater, with and without added $\mathrm{HgCl}_{2}$. The percent reduction in fluorescence yield was highly variable. It appears that either $\mathrm{Na}^{+}$or $\mathrm{Mg}^{2+}$ will prevent the inhibition of fluorescence by $\mathrm{Hg}^{2+}$, to an extent that depends on the concentration of the other cation, i.e. on the ionic strength of the solution. Fig. $2 \mathrm{~b}$ shows the relative fluorescence yield of BNAPH in the same solutions. While the reduction of fluorescence due to $\mathrm{Hg}^{2+}$ was significantly greater than for $4 \mathrm{MUF}$ in solutions of high ionic strength such as seawater, dependence on the ionic strength of the solution was weak and the loss of fluorescence was less than for 4MUF in solutions of low ionic strength. The bars in Fig. 2 represent slopes of standard curves with 3 points at decadally increasing concentrations; $r^{2}$ in all cases is $>0.9999$.

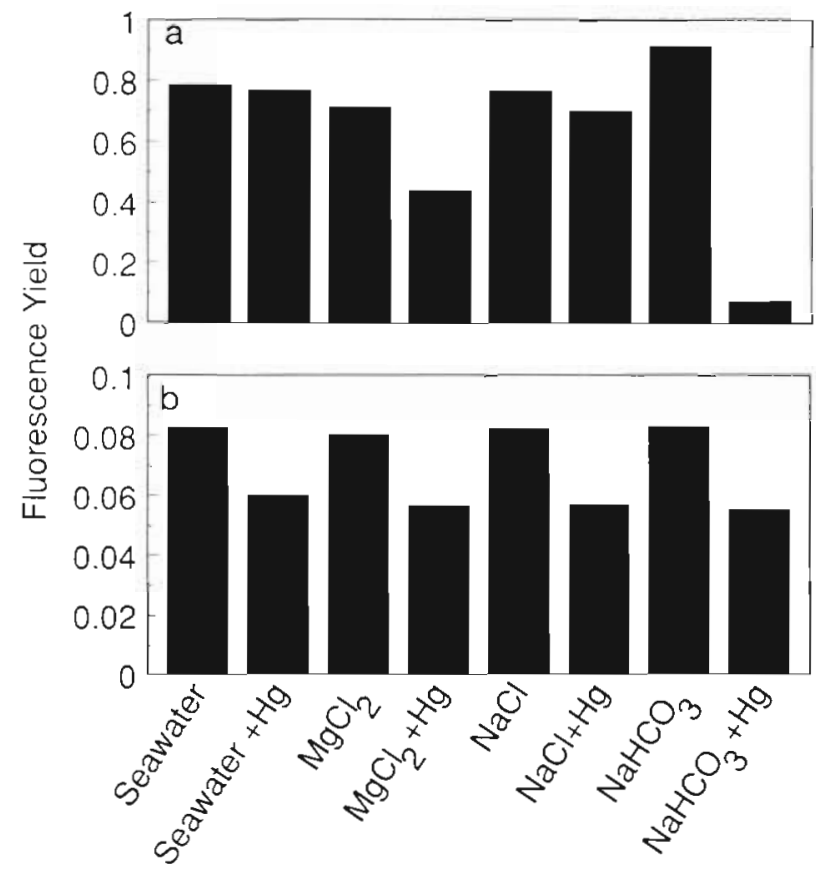

Fig. 2. Effect of $\mathrm{HgCl}_{2}$ on fluorescence of (a) 4-methylumbelliferone and (b) $\beta$-naphthylamine in solutions of $\mathrm{NaCl}, \mathrm{MgCl}_{2}$ and $\mathrm{NaHCO}_{3}$ at concentrations equivalent to seawater with $\mathrm{S}=35.0 \%\left(585 \mathrm{mM} \mathrm{NaCl}+2 \mathrm{mM} \mathrm{NaHCO}_{3}, 50 \mathrm{mM} \mathrm{MgCl}_{2}+\right.$ $2 \mathrm{mM} \mathrm{NaHCO}_{3}, 2 \mathrm{mM} \mathrm{NaHCO}_{3}$ ). Fluorescence yield is leastsquares linear regression of fluorescence (arbitrary units) on concentration with zero-intercept model (each curve is 3 points at decadally increasing concentration; $r^{2}=0.9999$ in all cases)

Mercuric chloride did not affect the excitation or emission spectra for either $4 \mathrm{MUF}$ or BNAPH in seawater. Fig. 3 illustrates the excitation (at constant emission wavelength), and emission (at constant excitation wavelength) spectra. Each curve is normalized to a constant maximum value, by a linear correction based on the percent offset at the fluorescence peak, to facilitate comparison of spectra.

To test the stability of fluorescence over time, we prepared 10 to 15 identical standards in subtropical North Pacific surface seawater with $4 \mathrm{mM} \mathrm{HgCl}_{2}$. The apparent concentration of each when it was thawed was determined as the relative fluorescence divided by the slope of the standard curve (fluorescence/ concentration) for freshly prepared standards. The stability of fluorescence over time in samples stored frozen at $-20^{\circ} \mathrm{C}$ is illustrated in Fig. 4

For $4 \mathrm{MUF}$ there was no reduction in apparent concentration over $18 \mathrm{mo}$ (Fig. 4a). The calculated slope of the Model I linear regression is positive $\left(0.003 \mathrm{nmol} \mathrm{l}^{-1}\right.$ $\left.\mathrm{d}^{-1}\right)$ but not significantly different from $0(\mathrm{p} \approx 0.30)$. The correlation coefficient ( $r$ ) for this relationship is 0.36 , which is not significant at the 0.05 level. Although the power of the test is insufficient to state with confidence 


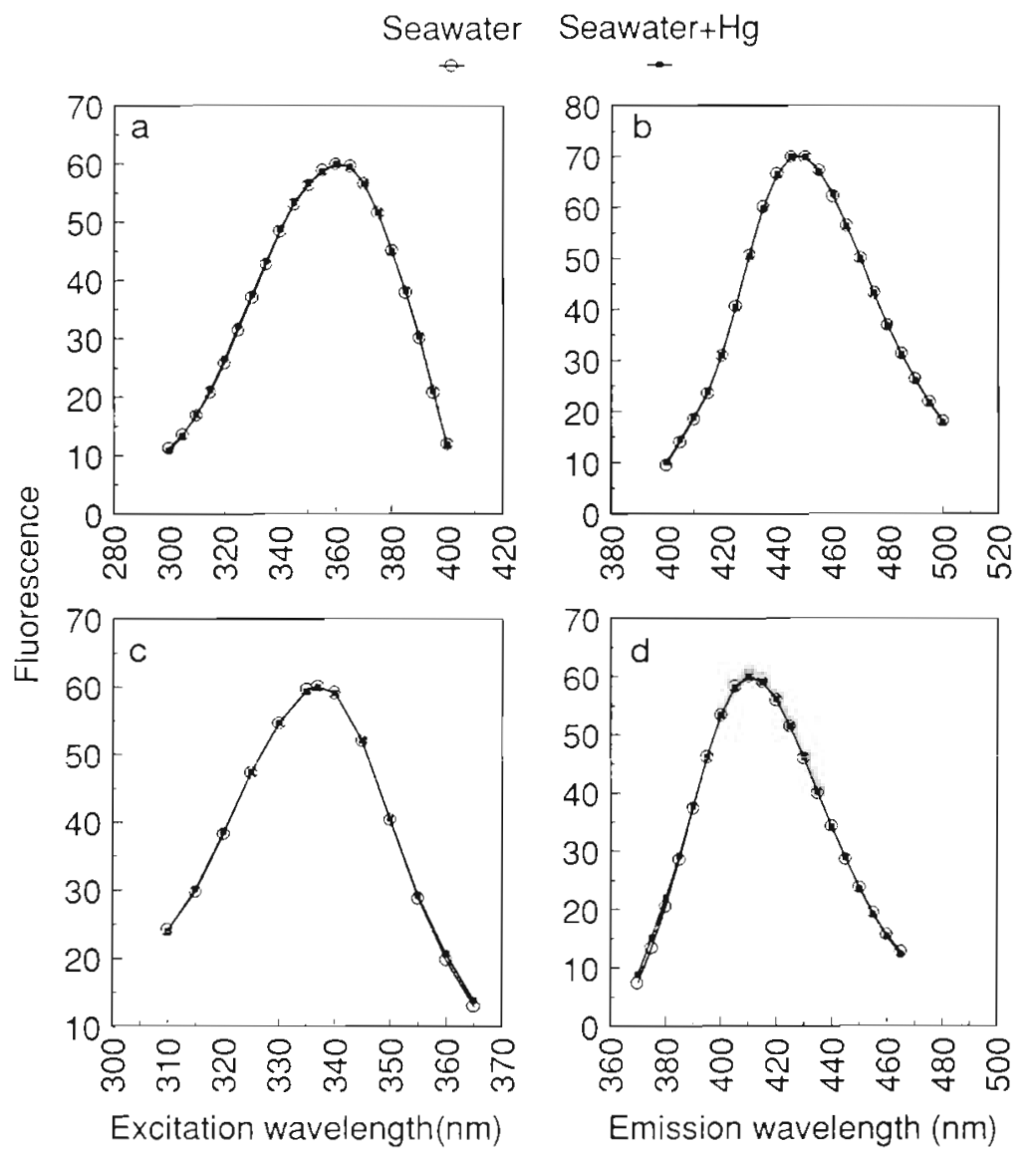

Fig. 3. Fluorescence spectra (arbitrary units) for 4-methylumbelliferone and $\beta$-naphthylamine in subtropical North Pacific surface seawater with and without $4 \mathrm{mM} \mathrm{HgCl}_{2}$. (a) Excitation spectrum for $4 \mathrm{MUF}$ with emission at $447 \mathrm{~nm}$; (b) emission spectrum for $4 \mathrm{MUF}$ with excitation at $360 \mathrm{~nm}$; (c) excitation spectrum for BNAPH with emission at $411 \mathrm{~nm}_{i}(\mathrm{~d})$ emission spectrum for BNAPH with excitation at $337 \mathrm{~nm}$. Spectra are normalized to constant peak fluorescence (linear correction)

that the slope of the line is not different from $0(\beta \geqslant 0.05)$, the absence of a significant correlation makes it difficult to speculate about changes in fluorescence over time.

For BNAPH there is a significant reduction in fluorescence over time (Fig. 4b). The correlation coefficient in this case is 0.941 , which is significant at the $\alpha=0.001$ level. The relationship is best fit by a nonlinear model; it appears that the rate of loss of fluorescence yield asymptotically approaches zero (i.e the apparent concentration drops to a constant value). In this experiment the asymptote falls at $-60 \%$ of the initial concentration. Because this experiment was conducted with multiple samples at a single concentration, it is possible that the percent loss is a function of the initial concentration. However, subsequent experiments have shown that the linearity of preserved 'standard curves' is maintained for at least $130 \mathrm{~d}$ and standards of different initial concentrations do not 'converge' to similar fluorescence (Fig. 4c).
Poisoned or heat-killed seawater controls are needed to correct for both autofluorescence and autohydrolysis of the substrate analogues. The substrate analogues used in ectoenzymatic analysis fluoresce strongly, but at different wavelengths from the free fluorogens. At the peak excitation and emission wavelengths for $4 \mathrm{MUF}$ the autofluorescence of substrate analogues like $4 \mathrm{MUF}$ - $\beta$-glucoside is minimal. There is some overlap of the excitation and emission spectra for the free fluorogens and the unhydrolyzed substrate analogues, so it is likely that at least some of the fluorescence observed in poisoned controls is due to the latter. However, the tendency for the fluorescence in killed controls prepared from a single stock solution to increase over time suggests that some fraction of the fluorescence in poisoned controls is due to autohydrolysis of the substrate analog, or hydrolysis by abiotic processes (Fig. 5). The rate of hydrolysis is low enough, however, that a single stock solution can be used for several weeks.

Hydrolysis of L-leucyl- $\beta$-naphthylamine to BNAPH appears to be catalyzed by $\mathrm{Hg}^{2+}$ (J.R.C. unpubl. data). The rate of increase of fluorescence in killed controls following poisoning is greater than what would be expected by abiotic hydrolysis alone. It is therefore desirable that killed controls be frozen immediately rather than incubated alongside the live samples. This prevents the killed controls from controlling for abiotic hydrolysis in the live samples during the incubation period, but this error is likely to be small (Hoppe 1993). Autohydrolysis of substrate analogues of this type appears to be an equilibrium process, that is, it occurs more or less instantaneously upon dilution and the percent dissociating decreases with increasing concentration. This results in a fluorescenceconcentration relationship that resembles the saturation kinetics of enzymes, so when working with 4 MUF derivatives with high background fluorescence (e.g. 4MUF-phosphate, 4MUF-N-acetyl-glucosamine) one must exercise caution when interpreting fluorescence as evidence of enzymatic activity.

\section{DISCUSSION}

Poisoning seawater with mercuric ion offers several advantages that may increase the sensitivity, precision, 

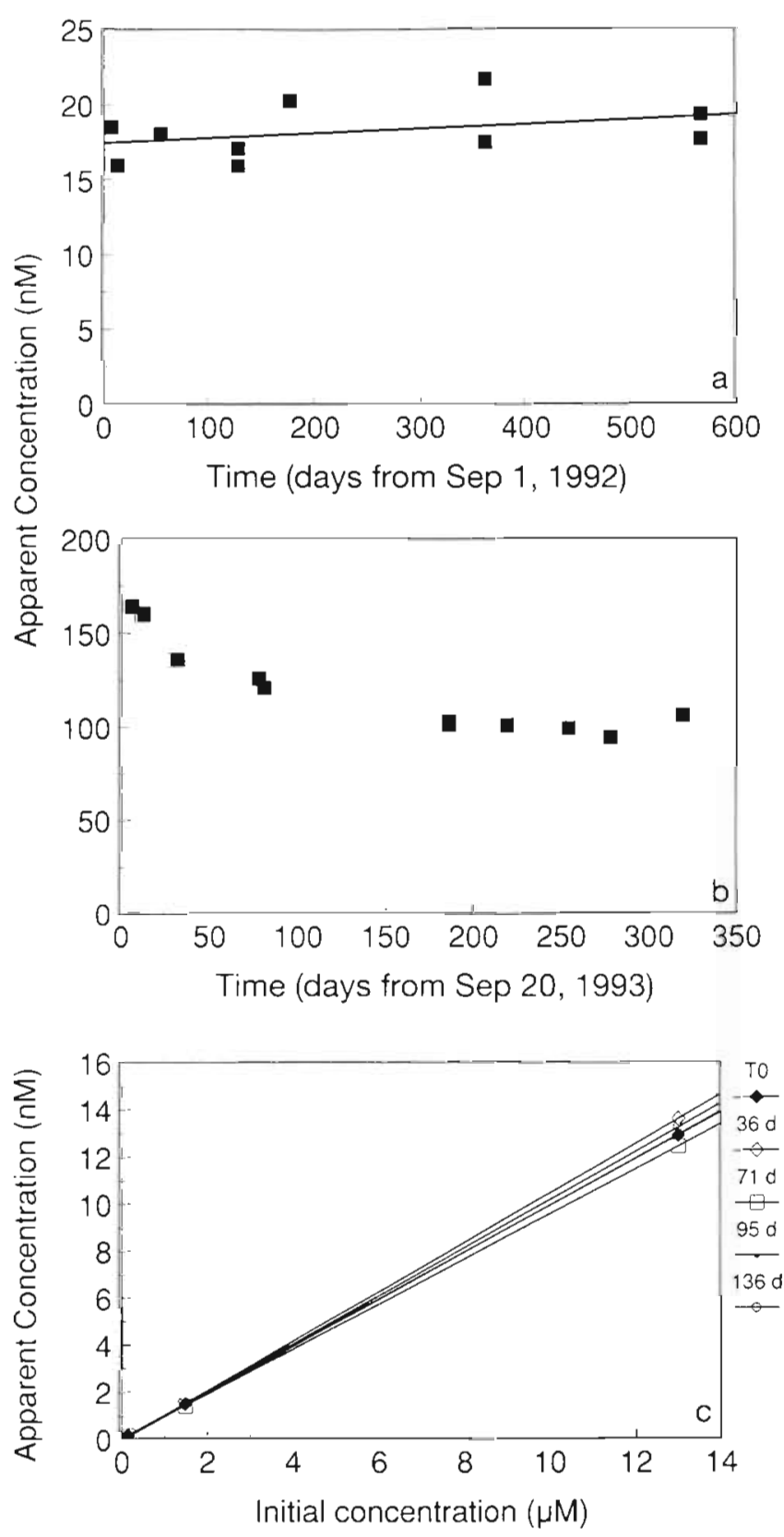

Fig. 4. Stability over time of fluorescence of (a) 4-methylumbelliferone (initial concentration $=16 \mathrm{nM}$ ), with Model I linear regression, (b) $\beta$-naphthylamine (initial concentration = $160 \mathrm{nM}$ ), and (c) $\beta$-naphthylamine over a wide range of initial concentrations, in replicate standards prepared in seawater with $4 \mathrm{mM} \mathrm{HgCl}_{2}$ and stored frozen at $-20^{\circ} \mathrm{C}$. T0: time zero. Apparent concentration is the fluorescence divided by the ratio of fluoresence to concentration (least-squares linear regression of fluorescence on concentration with zero-intercept model) for freshly prepared standards

and reliability of ectoenzyme assays, especially when working in oligotrophic waters. Mercuric ion can denature any active enzymes with minimal dilution. Alternative methods such as heat killing (Hoppe 1993) or

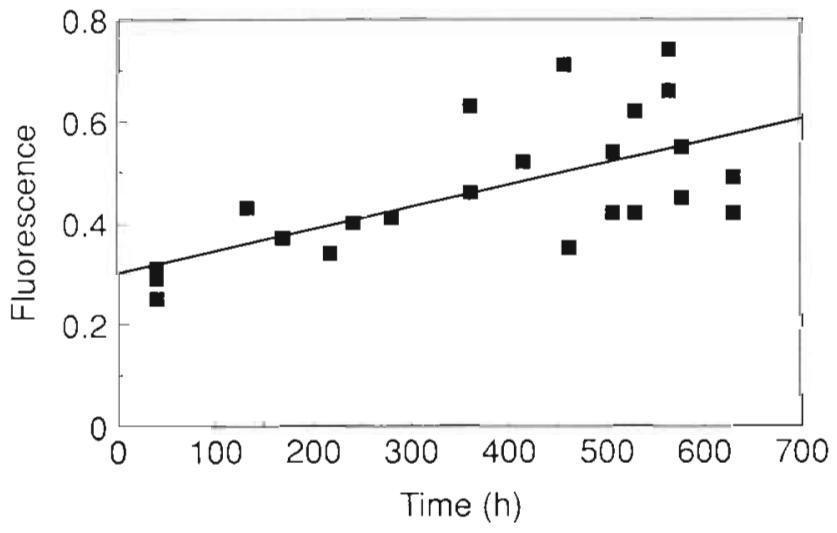

Fig. 5. Fluorescence (arbitrary units) of $\mathrm{Hg}^{2+}$-killed controls for $\beta$-glucosidase assay (1.6 $\mu \mathrm{M} 4$-MUF- $\beta$-glucoside, $4 \mathrm{mM}$ $\mathrm{HgCl}_{2}$ ) collected on RACER 4 (July-August 1992). Linear regression statistics: $a=0.30, b=4.3 \times 10^{-4}, \mathrm{r}^{2}=0.44, \mathrm{n}=24$. Time in hours from 00:00 h on July 15, 1992

adding acid or base (Vrba et al. 1992) may be successful if the fluorescence signal is strong relative to the background, but do not necessarily maximize the sensitivity of the assay.

Bringing the samples to a temperature of $100^{\circ} \mathrm{C}$ in a boiling water bath will denature most enzymes and this is the method used by most investigators (Hoppe 1993). Adding $\mathrm{HgCl}_{2}$ can be faster and simpler than heat killing, although with the proper apparatus (heat block or microwave oven) this difference is minimal. Preservation with $\mathrm{HgCl}_{2}$ is also possible in small boats where facilities to heat water to $100^{\circ} \mathrm{C}$ or to freeze samples are lacking. In addition it prevents hydrolysis during freezing and thawing if samples are stored frozen.

Adding base to inhibit enzymatic activity and to bring the $\mathrm{pH}$ to the optimal range for 4MUF fluorescence ( 10; Chróst \& Krambeck 1986) has been successful in fresh water (Vrba et al. 1992). This is more problematic in seawater due to its high natural buffering capacity and relatively high $\mathrm{pH}$ (7.5 to 8.5). Enzymes of marine bacteria may not be completely inactivated at $\mathrm{pH} 10$, so this approach is most suitable in fresh water with naturally low $\mathrm{pH}$.

Mercuric chloride does not affect the $\mathrm{pH}$ of seawater, even at high concentrations (10 to $20 \mathrm{mM}$ ). $\mathrm{HgCl}_{2}$ is highly soluble in seawater, and sufficient $\mathrm{Hg}^{2+}$ to completely denature the enzymes present can be added without diluting the sample significantly. $\mathrm{HgCl}_{2}$ can be added rapidly and samples are identical except for the variance in the volume added $(0.1 \pm 0.005 \mathrm{ml})$; variance in fluoresence among killed controls is small. After extensive experience with ectoenzymes in oligotrophic waters, we estimate that we can detect activities (of, for example, $\alpha$ - and $\beta$-glucosidase determined with $4 \mathrm{MUF}$ derivatives) as low as $5 \mathrm{pmol} \mathrm{l}^{-1} \mathrm{~h}^{-1}$ (based on $24 \mathrm{~h}$ 


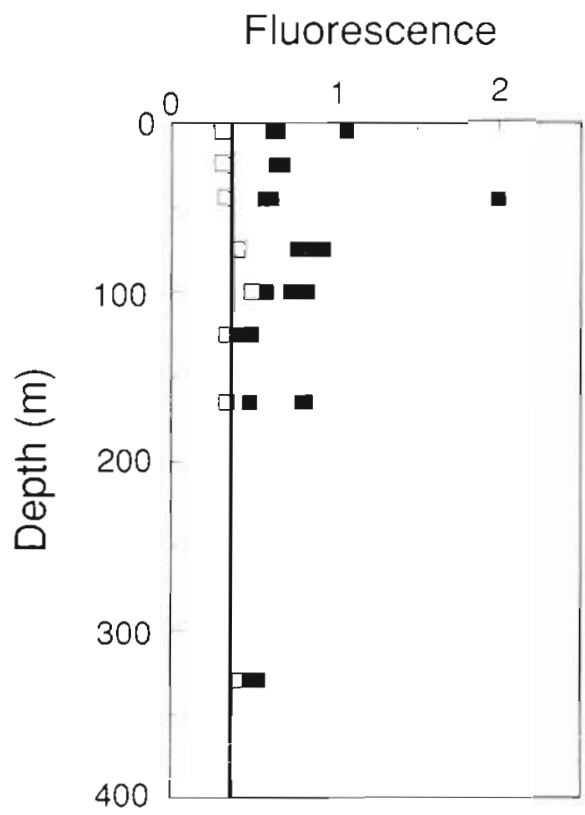

Fig. 6. Depth profile of fluorescence (arbitrary units) liberated from 4 MUF- $\beta$-glucoside over $24 \mathrm{~h}$ at $25^{\circ} \mathrm{C}$ at Station A.LOHA in the subtropical North Pacific Ocean $\left(22^{\circ} 45^{\circ} \mathrm{N}, 158^{\circ} 00^{\prime} \mathrm{W}\right)$. Solid squares are live samples. Open squares are $\mathrm{Hg}^{2+} \mathrm{Con}-$ trols; solid line shows the mean of these. One fluorescence unit represents $\sim 1.25 \mathrm{nM} 4 \mathrm{MUF}$

incubation), and accurately quantify activities 2 to 3 times this detection limit. For example, in the depth profile of $\beta$-glucosidase (BGase) activity shown in Fig. 6 , the activity at $330 \mathrm{~m}$ is about $7 \mathrm{pmol}^{-1} \mathrm{~h}^{-1}$, and the mean of triplicate samples is significantly $(p<0.01$, 1 -way ANOVA) greater than the mean of 8 killed controls

\section{Storage effects}

It is clear that samples incubated with 4 MUF derivatives can be stored for fairly long periods without losing fluorescence provided they are stored frozen and in the dark. We can not, however, state with certainty that the slope of the regression line is zero $(\beta \gg 0.05$; cf. Peterman 1990). The apparent increase in fluorescence is relatively small $(-2 \%$ over $100 \mathrm{~d})$ but it is probably not advisable to store samples for more than a few months.

BNAPH clearly loses fluorescence over time (Fig. 4b). This raises the question of possible higher order kinetics that will result in samples with different initial fluorescence 'converging' over time. This does not occur over periods up to $130 \mathrm{~d}$ (Fig. 4c) Standard curves spanning a wide ( 3 orders of magnitude) range of concentrations retained their linearity, and the percent reduction at the lower concentrations was similar to that observed in the experiment illustrated in Fig. 4 b. Samples using BNAPH should not be stored for more than a week or so, and other fluorogens such as 4 MUF may be preferable for this reason. L-leucylmethylcoumarinylamide (Leu-MCA) is widely used in aminopeptidase assays, and although we have not evaluated storage of MCA its chemical similarity to $4 \mathrm{MUF}$ suggests that it may be more amenable to storage than BNAPH.

\section{Freshwater applications}

Although we have not attempted field tests, it appears from our results that using $\mathrm{Hg}^{2+}$ as a preservative may be feasible in fresh water as well as seawater. Adding sodium chloride or other salts following poisoning restores the fluorescence of $4 \mathrm{MUF}$. BNAPH may not require additional cations, depending on the chemical composition of the lake or stream. The important point is that the inhibition of $4 M U F$ fluorescence by mercuric ion is reversible: the fluorescence of the solutions in Fig. 2 is the same regardless of the order of addition of the reagents. Loss of fluorescence of BNAPH during long-term storage is another issue; the reaction is probably irreversible, and may or may not be catalyzed by $\mathrm{Hg}^{2+}$.

\section{Detection of particle-associated activities}

Ectoenzyme activities in the interstitial spaces of many types of marine particles are much greater than in the surrounding water (Smith et al. 1992, Karner \& Herndl 1992). Diffusion of dissolved substances into aggregates is extremely slow. Because of the tortuosity of the pathways and the high probability of contact with reactive substances along the way, even substances found at high concentrations in the surrounding medium reach the interior spaces of the floc only gradually or, in some cases, not at all (cf. Witten \& Cates 1986). Because mercuric ions and substrate analogue molecules are diffusing into the floc along different pathways, and because mercuric ions may be scavenged by sulfhydryl or other reactive groups, $\mathrm{Hg}^{2+}$ will not completely inhibit enzymatic activity in water samples where a significant fraction of the activity is in the interior of aggregates. Fig. 7 shows that when aggregate material is incubated with $4 \mathrm{MUF}$ derivatives, the fluorescence liberated is much greater than background even in the presence of $4 \mathrm{mM} \mathrm{HgCl}_{2}$. In environments where such particles are expected to be abundant it may be advisable to use heat-killed controls in preference to $\mathrm{Hg}^{2+}$, or to filter the control samples before adding $\mathrm{Hg}^{2+}$. 


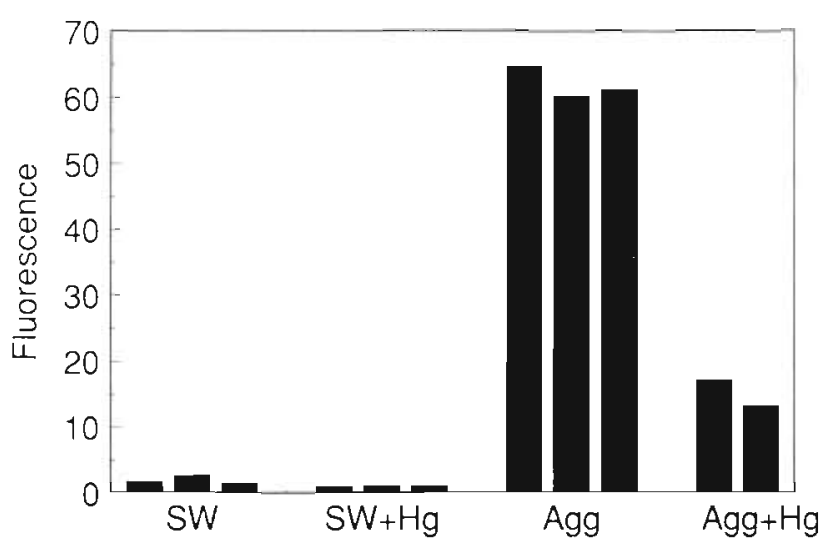

Fig. 7 Fluorescence (arbitrary units) liberated from 4 MUF- $\beta$ glucoside in aggregate material collected by SCUBA divers near Kewalo Basin, Oahu, Hawaii. Activity in aggregate material (Agg) with and without $\mathrm{HgCl}_{2}(4 \mathrm{mM})$ shown relative to ambient surface seawater ( $\mathrm{SW}$ ) and seawater $/ \mathrm{HgCl}_{2} \mathrm{Con}$ trols. One fluorescence unit represents $\sim 1.05 \mathrm{nM} 4 \mathrm{MUF}$

A useful application for this is that if $\mathrm{Hg}^{2+}$-killed controls are routinely collected at sea, they give a strong indication of whether or not activities are particle-associated. For example, when extremely high BGase activities were observed in the equatorial Pacific in 1992, low and consistent fluorescence in the killed controls demonstrated that this activity was entirely associated with the free-living bacterioplankton. In contrast, when unusually high BGase activities were observed in Marguerite Bay, Antarctica, near the receding annual pack ice (see Karl et al. 1992 for habitat description), fluorescence in the killed controls was high and variable, indicating that a significant fraction of the activity was particle-associated. However, this must not be interpreted as a quantitative metric of the activity associated with such particles.

\section{Alternative metal inhibitors}

Other metal cations such as $\mathrm{Cu}^{2+}$ and $\mathrm{Ni}^{2+}$ will inhibit bacterial ectoenzymes such as BGase (Fig. 8). $\mathrm{Ag}^{+}$is a poor choice because its solubility in seawater is too low for inhibitory concentrations to remain in solution. The solubilities of $\mathrm{Cu}^{2+}$ and $\mathrm{Ni}^{2+}$ are also less than the $4 \mathrm{mM}$ we routinely use for $\mathrm{Hg}^{2+}$, but these ions strongly inhibit at least some enzymes at their saturation concentration. Lower concentrations $(<100 \mu \mathrm{M})$ are not effective. $\mathrm{Ni}^{2+}$ has previously been shown to strongly inhibit marine bacterial activity at $5 \mathrm{mM}$ but not at $1 \mathrm{mM}$ (Gonye \& Jones 1973). We use $\mathrm{HgCl}_{2}$ because of its high solubility in seawater, the absence of $\mathrm{pH}$ effects, and its well-documented role as a potent and irreversible inhibitor of virtually all enzymes.

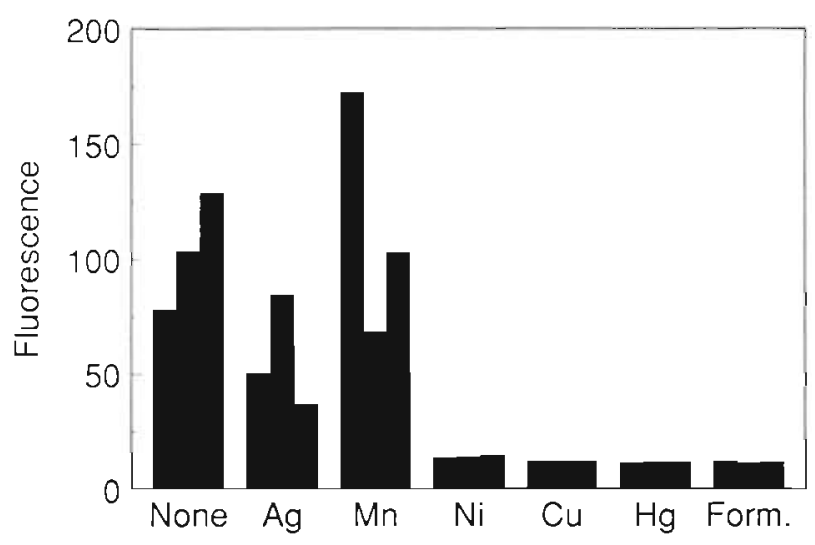

Fig. 8. Fluorescence (arbitrary units) of subtropical North Pacific surface seawater samples inocculated with $1.6 \mu \mathrm{M}$ $4 \mathrm{MUF}-\beta$-glucoside and stored for $29 \mathrm{~d}$ at room temperature $\left(\sim 22^{\circ} \mathrm{C}\right)$ with various potentially inhibitory metal cations. No inhibitor and $1 \%$ formalin are included for comparative purposes. All metal ions (Me) are added at $4 \mathrm{mM}$ as $\mathrm{MeCl}_{2}$, except $\mathrm{Ag}$ as $\mathrm{Ag}_{2} \mathrm{SO}_{4}$; there are 3 replicates for each treatment

\section{CONCLUSION}

Mercuric chloride has shown itself to be an excellent poison for preserving samples in which ectoenzyme activities are determined using fluorescent substrate analogues. It also provides a control for autofluorescence and abiotic hydrolysis of the substrate analogues. The loss of fluorescence due to added mercuric ion has been shown to be small for solvents of high ionic strength, such as seawater, and standard curves for the fluorogens $4 \mathrm{MUF}$ and $\mathrm{BNAPH}$ in $\mathrm{Hg}^{2+}$. poisoned seawater are linear to a high degree of certainty $\left(r^{2}>0.99\right.$ in all cases, $>0.999$ in most cases)

Although there are other options for preserving samples, such as heat, our technique offers the advantage of speed and simplicity, which in crowded labs aboard rolling ships frequently translates into reduced variance. In oceanic waters activities of most commonly studied ectoenzymes are low, and in live-incubation experiments where a control must be subtracted the sensitivity of the method ultimately depends on the variance among replicate samples and replicate controls. The advantages and disadvantages of using mercuric chloride may be summarized as follows: it is faster and simpler than heat-denaturing and prevents enzymatic activity during freezing and thawing, but it may be ineffective if a significant fraction of activity is associated with aggregate material, and involves use of a hazardous substance (U.S. Department of Transportation classification 'Poison B').

Acknowledgements. We thank the captains and crews of the RV 'Moana Wave' and the RV 'Nathaniel B. Palmer', and the Hawaii Ocean Time Series (HOT) staff for help with sample 
collection at sea. Charles Holloway collected the aggregate samples at Kewalo Basin. This research was supported by NSF grants OCE-93-01368 and OPP-91-18439 to D.M.K and a NASA Global Change Fellowship to J.R.C. SOEST Contribution 3858

\section{LITERATURE CITED}

Chróst RJ (ed) (1991) Microbial enzymes in aquatic environments. Springer-Verlag, Berlin

Chróst RJ, Krambeck HJ (1986) Fluorescence correction for measurements of enzyme activity in natural waters using methylumbelliferyl substrates. Arch Hydrobiol 106:79-90

Chróst RJ, Velimirov B (1991) Measurement of enzyme kinetics in water samples: effect of freezing and soluble stabilizer. Mar Ecol Prog Ser 70:93-100

Gonye ER Jr, Jones GE (1973) An ecological survey of open ocean and estuarine microbial populations. II. The oligodynamic effect of nickel on marine bacteria. In: Stevenson LH, Colwell RR (eds) Estuarine microbial ecology. University of South Carolina Press, Columbia, p 243-257

Hoppe HG (1983) Significance of exoenzymatıc activities in the ecology of brackish water: measurements by means of methylumbelliferyl substrates. Mar Ecol Prog Ser 11. 299-308

Hoppe HG (1991) Microbial extracellular enzyme activity: a new key parameter in aquatic ecology. In: Chróst RJ (ed) Microbial enzymes in aquatic environments. SpringerVerlag, Berlin, p 60-83

This article was presented by B. \& E. Sherr (Senior Editorial Advisors), Corvallis, Oregon, USA
Hoppe HG (1993) Use of fluorogenic model substrates for extracellular enzyme activity (EEA) of bacteria. In: Kemp PF, Sherr BF, Sherr EB, Cole JJ (eds) Handbook of methods in aquatic microbial ecology. Lewis, Boca Raton, p 423-431

Karl DM, Amos A, Holm Hansen O, Huntley ME, Vernet $M$ (1992) RACER: the Marguerite Bay ice-edge reconnaissance. Antarct J US 27:175-177

Karner M, Herndl GJ (1992) Extracellular enzymatic activity and secondary production in free-living and marinesnow-associated bacteria. Mar Biol 113:341-347

Peterman RM (1990) Statistical power analysis can improve fisheries research and management. Can J Fish Aquat Sci 47:2-15

Royer GP (1982) Fundamentals of enzymology. John Wiley and Sons, New York

Smith DC, Simon M. Alldredge AL, Azam F (1992) Intense hydrolytic enzyme activity on marine aggregates and implications for rapid particle dissolution. Nature 359: 139-142

Somville $M$, Billen $G$ (1983) A method for determining exoproteolytic activity in natural waters. Limnol Oceanogr 28 : $190-193$

Vrba J, Nedoma J, Simek K, Seda J (1992) Microbial decomposition of polymer organic matter in a reservoir: activity of $\alpha$ - $\beta$-glucosidase, and $\beta-N$-acetylglucosaminidase and uptake of $\mathrm{\beta}$-N-acetylglucosamine. Arch Hydrobiol 126: $193-211$

Witten TA, Cates ME (1986) Tenuous structures from disorderly growth processes. Science 232:1607-1612

Manuscript first received: September 20, 1994

Revised version accepted:December 19, 1994 